\title{
Application of Atlas-based global shape and local contraction analysis to single-ventricle congenital heart disease
}

\author{
Avan Suinesiaputra1*, Genevieve E Farrar², Kathleen Gilbert', Sanjeet Hegde ${ }^{3}$, Andrew D McCulloch², Jeff Omens²,
} James C Perry ${ }^{3}$, Alistair Young ${ }^{1}$

From 19th Annual SCMR Scientific Sessions

Los Angeles, CA, USA. 27-30 January 2016

\section{Background}

Improvements in palliative surgery for infants born with single ventricle heart defects have increased their survival rate into adulthood, but the risk of developing heart failure remains high. The ventricles remodel to geometric extremes, making statistical comparison with the normal population difficult beyond the assessment of mass and volumes. We present a new method for evaluating cardiac geometry and systolic contraction variations in patients with single ventricle physiology with respect to the normal range of end-diastolic (ED) and end-systolic (ES) left ventricle (LV) shapes seen in the asymptomatic population.

\section{Methods}

Cardiac MRI of four single-ventricle patients with tricuspid atresia and $>10$ years post-Fontan surgery were analyzed using custom software (CIM, Auckland, New Zealand). EDV $(\mathrm{ml})=\{183.5,122.9,123.6,77.7\}$, ESV $(\mathrm{ml})$ $=\{97.7,60.9,72.7,35.3\}, \mathrm{EF}(\%)=\{46.8,50.5,41.2,54.6\}$, and LVM $(\mathrm{g})=\{143.4,116.8,134.9,63.3\}$. Each patient's LV shape was projected onto Principal Component Analysis (PCA) models previously derived from 1,991 asymptomatic volunteers [1], resulting as patient's principal scores for each PCA component. For local contraction analysis, thin-plate spline registration aligned LV shapes at ED onto the mean ED shape of the asymptomatic group. The corresponding ES shape was then deformed following the same ED shape alignment causing each patient LV to start the contraction from the same shape. ES points were compared statistically using the Mahalanobis distance.

\section{Results}

Geometric LV shape extremes were identified at ED for P2 and P3 (Figure 1), even though LV volumes and masses were within normal ranges. Standardised principal scores of the four patients with respect to the asymptomatic group from the first five components are shown in Table 1. Individually, P4 had a small ventricular size, while P3 had a large inclination of the basal region affecting the LV outflow tract variation. P2 had a shorter height, a lower basal plane, and a thinner wall. For regional contraction, Figure 1 shows ES points after the ED alignment that lie outside the asymptomatic distributions. Each patient showed different patterns of local contraction abnormalities. P1 had abnormal lateral and septal epicardial wall contraction, while P3 shows abnormal contraction in multiple regions.

\section{Conclusions}

Atlas-based statistical shape analysis allows for identification of abnormal shape characteristics beyond mass and volume, as well as regional systolic contraction patterns. This may provide valuable new measures of disease progression and remodeling into heart failure relative to population norms.

\section{Authors' details}

'Department of Anatomy with Radiology, University of Auckland, Auckland, New Zealand. ${ }^{2}$ Department of Bioengineering, Universeity of California San Diego, San Diego, CA, USA. ${ }^{3}$ Division of Cardiology, Rady Children's Hospital, San Diego, CA, USA. 


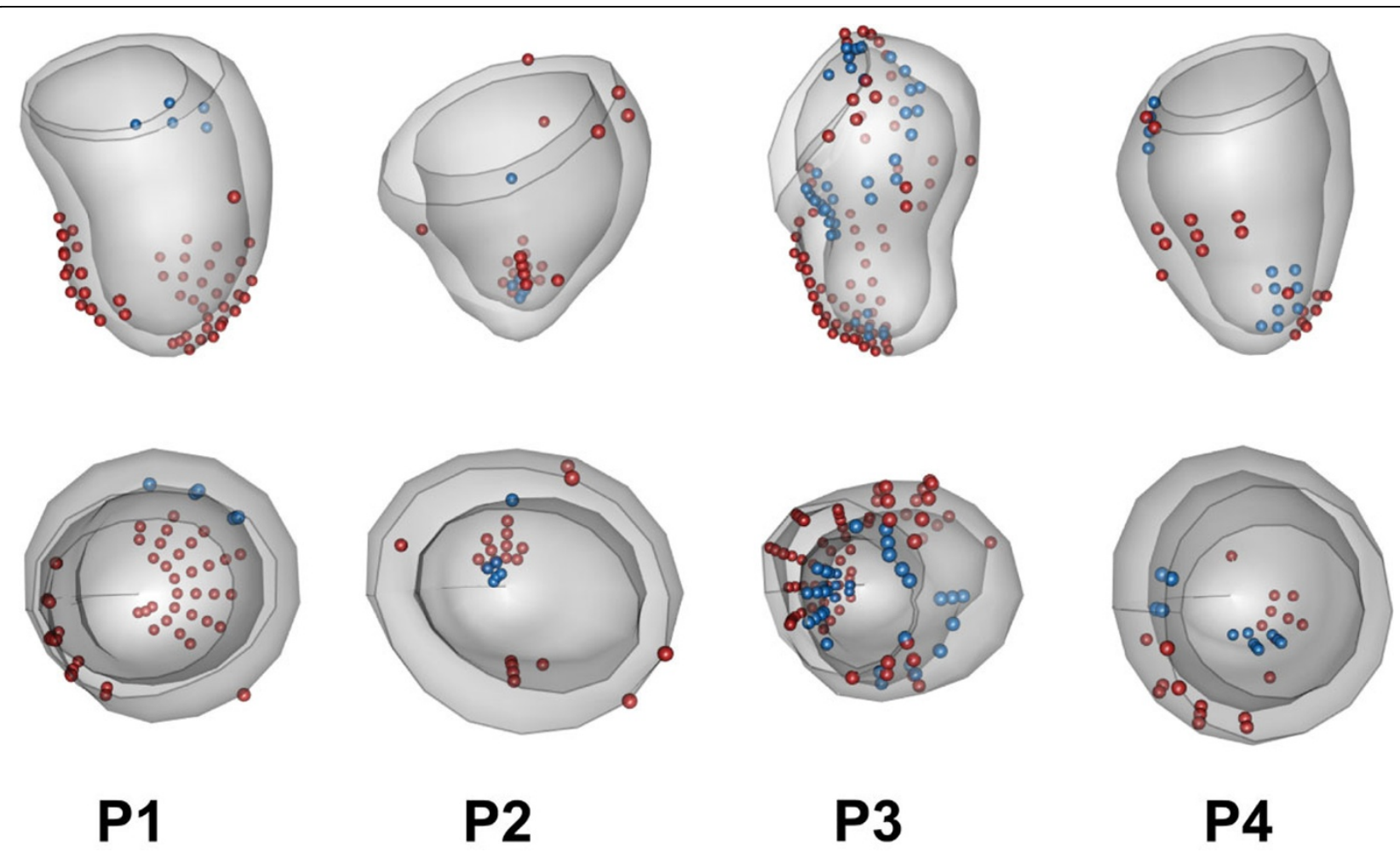

Figure 1 LV shapes at ED from four single-ventricle patients. Spheres show ES points that lie outside the asymptomatic distributions (blue points are on endosurface, red points are on episurface). The bottom row shows view from the base with septum on the left side.

Table 1 Principal scores of four single-ventricle patients (P1-P4) after projecting onto PCA models of 1,991 asymptomatic subjects.

\begin{tabular}{|c|c|c|c|c|c|c|}
\hline PC & Geometry variation & Pct & P1 & P2 & P3 & P4 \\
\hline \multicolumn{7}{|c|}{ PCA-ED } \\
\hline 1 & Size & $44.5 \%$ & -0.9 & 1.6 & -0.7 & 2.2 \\
\hline 2 & Base Plane & $10.6 \%$ & 0.6 & 3.1 & 1.6 & -0.2 \\
\hline 3 & Basal Slice & $9.2 \%$ & 1.3 & 1.4 & -6.6 & 0.5 \\
\hline 4 & Longitudinal (height) & $6.8 \%$ & -1.5 & -3.1 & -1.6 & 0.1 \\
\hline 5 & Apical Slice & $5.0 \%$ & -0.4 & -2.0 & -1.5 & -0.4 \\
\hline \multicolumn{7}{|c|}{ PCA-ES } \\
\hline 1 & Size & $43.1 \%$ & -1.3 & 0.4 & -0.8 & 1.5 \\
\hline 2 & LV Outflow Tract & $11.0 \%$ & -1.2 & -1.8 & 3.3 & -2.7 \\
\hline 3 & Basal Thickness & $7.2 \%$ & -0.2 & -2.7 & -0.8 & 0.8 \\
\hline 4 & Mid-lateral Wall & $5.0 \%$ & -3.4 & -1.3 & 2.9 & -2.3 \\
\hline 5 & Wall Thickness & $4.3 \%$ & 1.3 & 1.2 & 4.2 & 1.4 \\
\hline
\end{tabular}

Only the first five principal components $(\mathrm{PC})$ are shown. Pct $=$ percentage of variance explained. Values are the standardised principal scores; highlighted with bold face are values outside \pm 2 standard deviation.

Published: 27 January 2016

\section{Reference}

1. Medrano-Gracia P, et al: JCMR 2014.
doi:10.1186/1532-429X-18-S1-P154

Cite this article as: Suinesiaputra et al:: Application of Atlas-based global shape and local contraction analysis to single-ventricle congenital heart disease. Journal of Cardiovascular Magnetic Resonance 2016 18(Suppl 1): P154.

Submit your next manuscript to BioMed Central and take full advantage of:

- Convenient online submission

- Thorough peer review

- No space constraints or color figure charges

- Immediate publication on acceptance

- Inclusion in PubMed, CAS, Scopus and Google Scholar

- Research which is freely available for redistribution 